\title{
Optimal Allocation of PHEV Parking Lots to Minimize Distribution System Losses
}

\author{
Mahmud Fotuhi-Firuzabad, Ali Abbaspour, Mohsen Mazidi, Mohamamd Rastegar
}

\begin{abstract}
To tackle the air pollution issues, Plug-in Hybrid Electric Vehicles (PHEVs) are proposed as an appropriate solution. Charging a large amount of PHEV batteries, if not controlled, would have negative impacts on the distribution system. The control process of charging of these vehicles can be centralized in parking lots that may provide a chance for better coordination than the individual charging in houses. In this paper, an optimization-based approach is proposed to determine the optimum PHEV parking capacities in candidate nodes of the distribution system. In so doing, a profile for charging and discharging of PHEVs is developed in order to flatten the network load profile. Then, this profile is used in solving an optimization problem to minimize the distribution system losses. The outputs of the proposed method are the proper place for PHEV parking lots and optimum capacity for each parking. The application of the proposed method on the IEEE-34 node test feeder verifies the effectiveness of the method.
\end{abstract}

Keywords-Plug-in Hybrid Electric Vehicle (PHEV), PHEV parking lot, $\mathrm{V} 2 \mathrm{G}$.

\section{INTRODUCTION}

$\mathrm{V}$ EHICLES with internal combustion engines are the main global pollutant of the environment. Greenhouse gas emissions are contributing to ozone depletion, climate change, and global warming. Electric Vehicles (EVs) can help the environment by reducing the use of fossil fuels. EVs can reduce $\mathrm{CO}_{2}$ emissions by more than 75 percent compared to internal combustion vehicles, even counting the emissions of the fossil-fueled power plants that supply high demand of EV batteries [1], [2]. Renault car factory recently made public a report that provides a fair assessment by comparing an electric version of its "Fluence" sedan with gas and diesel-powered versions of the same car. The report makes clear that electric cars are, indeed, better for the environment [3].

EVs use an onboard battery supply to power an electric motor for propulsion. New generation of EVs that can be recharged by connecting to power grid are called Plug-in Hybrid Electric Vehicles (PHEVs). They are also capable of giving their stored energy (in the battery) to the grid, which is referred to as Vehicle to Grid (V2G) ability. Each PHEV is specified by an all-electric range (AER) property and called PHEV-x, where $\mathrm{x}$ is its AER. AER is the distance that PHEV can be driven on battery power. The amount of energy that is remained in the PHEV battery is called state of charge (SOC) of the PHEV.

Mahmud Fotuhi-Firuzabad, Ali Abbaspour, Mohsen Mazidi, Mohamamd Rastegar are with the Sharif University of Technology, Tehran, Iran (e-mail: fotuhi@sharif.edu, abbaspour@sharif.edu,_m_mazidi@ee.sharif.edu, rastegar_m@ee.sharif.edu).
Since PHEVs are connected into the power grid to be recharged, concerns were raised about the negative impacts of PHEVs' charging on the distribution network. Charging and discharging of PHEVs can be modeled like a new kind of load in the power grid. The effects of this load on the power grid can be even more challenging, if PHEVs' penetration level increases. Thus, the main concern about PHEVs is how to control and manage their charging process. In [4], [5], it is shown that about 93 to 96 percent of day-time, electric vehicles are parked. It seems that if there was a way to charge and discharge PHEVs all in one place, the charging control and management process would be easier. The charging parking lots provide such an opportunity for charging the PHEVs in a concentrated manner. Charging parking lot is a site where infrastructures for charging PHEVs are provided. When PHEVs are parked in such parking lots, the V2G application is feasible. The PHEV owners park their car in the parking and the parking operator monitors and controls the charging process. The PHEV owners expect to have a fully charged battery when leaving the charging parking lot.

It seems that, finding the optimal location and capacity for PHEV parking lots are prior to control the PHEV charging in such a parking lot. Appropriate decision in this case can be beneficial to the customers, suppliers, and distribution network operators.

Despite numerous studies on PHEV charging demand and control, PHEV parking allocation has not been deeply studied. For example, in [6], [7], allocation of parking lots considering V2G capability for active and reactive loss reduction is studied, where power flow is calculated based on the backward-forward sweep method. In [8], placement of DGs and PHEV parking lots are effectuated simultaneously, without considering the proper charging profile for PHEVs. In [9], a simultaneous optimum allocation of parking lots and photovoltaic system for energy loss reduction and voltage profile improvement in a $24-$ hour period is considered.

In this paper, allocating charging parking lot is effectuated to minimize the distribution network losses. In so doing, a profile for PHEV charge and discharge referred to as PHEV Charging Profile (PCP) is required. In developing PCP, flattening residential load profile is taken into account. PHEV characteristics should be determined to achieve PCP. To obtain vehicle specifications, National Household Travel Survey (NHTS) [10] is studied and analyzed. The Number of PHEVs is calculated by using the total number of vehicles in the network and PHEV penetration level. Also, PHEV arrival and departure times to and from parking lots is attained by investigating the published surveys. In addition, PHEV 
specifications can be achieved from car producer companies. The simulations are run using the generated PCP to minimize the distribution system loss with the help of OpenDSS software linked with MATLAB [13]. The outputs of the optimizationbased problem are the PHEV parking capacities at the candidate nodes of the distribution system.

The rest of this paper is arranged as follows. Section II extracts the PHEVs' arrival and departure time to and from the parking, PHEV battery SOC at the arrival time, and other battery specifications such as the battery capacity and AER from the available reports and papers. Section III presents the PCP development to flatten total network load profile. Section IV demonstrates the problem formulation and allocation algorithm. Then, the proposed approach is applied to IEEE-34 node test feeder in Section V to justify the effectiveness of the propounded method. Finally, the paper is concluded in section VI.

\section{Extracting Necessary Data to DeVelop PCP}

In this section, the required data to develop PCP is extracted from the reports. Vehicle arrival and departure time to and from the parking, different vehicle classes, the vehicle distribution in the network, and PHEV specifications are presented in this section.

The vehicle arrival and departure time is achieved by investigating public parking surveys [14], [15]. The gathered information is summarized in Table I. As it can be seen in Table I, there are 24 parking lots, whose capacities are around 100 vehicles, each. For the sake of simplicity, the data in Table I is clustered into three sets. The clustered information and their associated shares among the vehicles, which are parked in the parking, are presented in Table II.

PHEVs specifications (battery capacity, AER, etc.), as mentioned before, are provided by the car companies or electric utilities [11], [12]. The standard specification for a PHEV-33 is shown in Table III. This specification can be easily recalculated for PHEVs with different AERs and definite specific energy required (SER) using a simple equation like (1):

$$
C=S E R \times A E R
$$

where, $\mathrm{C}$ is the battery capacity and SER actually is the energy consumed per mile and is constant for a specific type of PHEV (in terms of AER).

To calculate total energy needed to charge PHEVs' batteries, various data are required, including: 1) Total number of PHEVs in the network; 2) Vehicle Class (Sedan, SUV, etc.); 3) PHEV type (based on AER); 4) SOC of PHEVs at the arrival time; and 5) Charger efficiency.

The first data, i.e., the number of vehicles, is obtained from NHTS 2009 and is shown in Table IV. The number of PHEVs is then calculated by weighting total number of vehicles by PHEV penetration level. The next two data, vehicle classes and PHEV types, are presented in Tables V and VI, in which c and $\mathrm{Z}$ are respectively the vehicle classes and PHEV types indices.
It is assumed that PHEV initial SOCs can randomly take five discrete values, i.e. $0.1,0.3,0.5,0.7$, and 0.9 . With all of the information discussed, total energy needed to charge all PHEVs $\left(E_{\text {total }}\right)$ is presented in (2):

$$
E_{\text {total }}=\sum_{z=1}^{3} \sum_{c=1}^{4} \sum_{j=1}^{5} \eta N \times V C_{c} \times P T_{z} \times\left(1-S O C_{j}\right) P_{\text {SOC }_{j}}
$$

where $E_{\text {total }}$ is the total energy needed to charge PHEVs, $\eta$ is the charger efficiency; $\mathrm{N}$ is the total number of PHEVs, $V C_{c}$ is the percentage of each class of vehicles according to Table $\mathrm{V}$, $\mathrm{PT}_{z}$ represents percentage of PHEVs with specific AERs according to Table VI, $\mathrm{SOC}_{\mathrm{j}}$ is one of the 5 discrete SOC levels previously discussed, and $P_{\mathrm{SOC}_{j}}$ shows the percentage of PHEVs with the specific $\mathrm{SOC}_{\mathrm{j}}$ value which is randomly obtained.

TABLE I

\begin{tabular}{|c|c|c|c|}
\hline Parking No. & Parking name & $\begin{array}{c}\text { Peak hour } \\
\text { arrivals }\end{array}$ & $\begin{array}{l}\text { Peak hour } \\
\text { departures }\end{array}$ \\
\hline 1 & Maritime Museum & 07:30-08:00 & 18:00-19:00 \\
\hline 2 & Riverway Park A & 07:00-08:00 & $18: 30-19: 30$ \\
\hline 3 & Riverway Park B & $07: 30-08: 30$ & 18:00-19:00 \\
\hline 4 & Tesco Supermarket & 07:00-08:00 & $17: 15-18: 45$ \\
\hline 5 & Lamont Place - East & $07: 00-08: 30$ & $17: 30-19: 00$ \\
\hline 6 & Lamont Place - West & 07:00-08:00 & $18: 30-19: 30$ \\
\hline 7 & Friars Croft & $07: 30-08: 30$ & $16: 30-18: 30$ \\
\hline 8 & Rivergate Center A & 07:00-08:00 & 18:00-19:00 \\
\hline 9 & Rivergate Center B & 07:30-09:00 & $17: 00-18: 30$ \\
\hline 10 & Rivergate Center C & 07:00-08:00 & $18: 00-19: 00$ \\
\hline 11 & Railway Station & $07: 15-08: 15$ & $18: 15-19: 15$ \\
\hline 12 & Broomlands Drive & 07:00-08:00 & $17: 30-18: 30$ \\
\hline 13 & Parterre & 08:00-09:00 & $18: 30-19: 30$ \\
\hline 14 & West Road & $07: 30-08: 30$ & 18:00-19:00 \\
\hline 15 & Multi Store & $10: 15-11: 15$ & $16: 30-17: 30$ \\
\hline 16 & Peden Place & $09: 30-10: 30$ & $16: 00-17: 00$ \\
\hline 17 & Kirkgate & 10:00-11:00 & $16: 00-17: 00$ \\
\hline 18 & Townhouse & $10: 30-11: 30$ & $16: 30-17: 30$ \\
\hline 19 & East Road South & 10:00-11:00 & $16: 45-17: 45$ \\
\hline 20 & East Road Service & $10: 30-11: 30$ & $16: 00-17: 00$ \\
\hline 21 & ALDI Supermarket & $12: 30-13: 30$ & $17: 00-18: 00$ \\
\hline 22 & East Road Park & $11: 00-12: 00$ & $17: 30-18: 30$ \\
\hline 23 & East Road North & $11: 30-12: 30$ & $16: 30-17: 30$ \\
\hline 24 & Quarry Road & $11: 30-12: 30$ & $17: 00-18: 00$ \\
\hline
\end{tabular}

VEHICLES ARRIVAL AND DEPARTURE TIMES

TABLE II

Clustered Vehicles ARrival AND DePARTURE TIMES

\begin{tabular}{cc}
\hline \hline Vehicles in parking (percentage) & Time intervals in parking \\
\hline $58.33 \%$ & $\sim 7^{\mathrm{AM}}-\sim 19^{\mathrm{PM}}$ \\
$25 \%$ & $\sim 10^{\mathrm{AM}}-\sim 16^{\mathrm{PM}}$ \\
$16.67 \%$ & $\sim 11^{\mathrm{AM}}-\sim 17^{\mathrm{PM}}$ \\
\hline \hline
\end{tabular}

TABLE III

PHEV-33 STANDARD SPECIFICATIONS

\begin{tabular}{ccc}
\hline \hline Vehicle Class & SER $[\mathrm{kWh} /$ mile $]$ & Battery Capacity $(\mathrm{C})$ \\
\hline Compact Sedan & 0.26 & 8.6 \\
Mid-size Sedan & 0.3 & 9.9 \\
Mid-size SUV & 0.38 & 12.5 \\
Full-size SUV & 0.46 & 15.2 \\
\hline
\end{tabular}


TABLE IV

VEHICLE DISTRIBUTION IN HOUSES

\begin{tabular}{cc}
\hline \hline No. of vehicles in each house & Percentage of houses (NHTS) \\
\hline 0 & $3.40 \%$ \\
1 & $25.26 \%$ \\
2 & $42.61 \%$ \\
3 & $18.74 \%$ \\
4 & $6.57 \%$ \\
5 & $2.18 \%$ \\
More than 5 & $1.24 \%$ \\
\hline \hline
\end{tabular}

TABLE V

VEHICLE CLASSES

\begin{tabular}{ccccc}
\hline \hline $\begin{array}{c}\text { Vehicle class } \\
\text { (VC) }\end{array}$ & $\begin{array}{c}\text { Compact } \\
\text { Sedan }\end{array}$ & $\begin{array}{c}\text { Mid-size } \\
\text { Sedan }\end{array}$ & $\begin{array}{c}\text { Mid-size } \\
\text { SUV }\end{array}$ & $\begin{array}{c}\text { Full-size } \\
\text { SUV }\end{array}$ \\
\hline $\mathrm{c}$ & 1 & 2 & 3 & 4 \\
Percentage & 52 & 11 & 23 & 14 \\
\hline \hline
\end{tabular}

TABLE VI

\begin{tabular}{cccc}
\multicolumn{4}{c}{ PHEV TYPES MARKET SHARE } \\
\hline \hline PHEV type (PT) & PHEV-30 & PHEV-40 & PHEV-60 \\
\hline $\mathrm{z}$ & 1 & 2 & 3 \\
Percentage & 21 & 59 & 20 \\
\hline
\end{tabular}

\section{DEVELOPING PCP CURVE}

Now that all required information is gathered, a PCP can be developed. As mentioned before, the proper objective in developing PCP can be flattening the present network load profile. According to network topography and thus number of houses in the network, the total load profile can calculated. The number of houses can be estimated by

$$
N_{\text {house, total }}=\left(N_{D} N_{P} N_{H}\right)+\left[\left(L_{\text {spot }}\right) / L_{\text {avg }}\right]
$$

where, $\mathrm{N}_{\text {house,total }}$ is the total number of houses in the network, ND is the number of distributed loads, NP is the number of phases of a distributed load, $\mathrm{NH}$ is number of houses assigned to each phase (which is assumed to be 3 here), Lspot is the total residential spot load, and finally Lavg is the average household load. Total number of vehicles in such a network is calculated based on the distribution of PHEVs in Table IV.

As shown in Table II, three clusters were considered for duration of vehicles presence in the parking. The PCP should be developed for each class. Then, they are aggregated to achieve a final PCP for all times. The objective function for developing PCP is:

$$
\underset{t=1}{\operatorname{minimize}}\{\operatorname{var}(L P(t)+P C P(t))\}
$$

where, $L P(t)$ and $P C P(t)$ are respectively the load profile of network and the PCP amount at the time interval $t$. As the constraint of (4), the area under the $P C P(t)$ during the horizon time should be equal to $E_{\text {total }}$ calculated in (3). It should be noted that $\mathrm{n}$ is the number of time intervals and is directly depended on the duration that vehicles are parked in the parking lot. Also although charging and discharging rates are not discussed here, they are considered in the case study section.

\section{PROBlem Formulation}

It was pointed before that the objective of charging parking lot allocation in this paper is to minimize total network loss. This goal should be considered for all time intervals that vehicle is parked in the parking and also for all buses of the grid that charging parking lots are going to be positioned at.

It is also worthwhile to mention that the candidate nodes for installing charging parking lots are purposed by a traffic engineer or a related organization like municipality. Among these purposed locations the best capacity of them are chosen in this paper.

The objective function is:

$$
\operatorname{minimize}\left\{\operatorname{loss}\left(\sum_{t=1}^{n} \sum_{k=1}^{m} L P^{k}(t)+x^{k} P C P(t)\right)\right\}
$$

subjected to following constraints:

$$
\begin{array}{ll}
0 \leq \operatorname{SOC}_{i}(t) \leq 1, & \forall i \\
\operatorname{SOC}_{i}\left(d_{i}\right) \geq S O C_{i, d e s}, & \forall i \\
\mathrm{~V}_{p u}^{k}(t) \geq \mathrm{V}_{p u, \text { min }}^{k}, & \forall t, \forall k \\
\begin{cases}C R_{i}(t) \leq C R_{i}^{\text {max }} \\
D R_{i}(t) \leq D R_{i}^{\text {max }}\end{cases} & \forall t \\
C^{k}=x^{k} N_{P H E V}, & \forall k \\
C^{k} \leq C_{\text {max }}^{k}, & \forall k
\end{array}
$$

where, $\mathrm{i}, \mathrm{t}$, and $\mathrm{k}$ are respectively the indices of PHEVs, time intervals, and candidate nodes; $L P^{k}(t)$ is the network load before PHEV charging load, that is specified for each bus and in each time interval; the coefficient $x^{k}$ shows the share of node number $\mathrm{k}$ (from candidate buses) from total charging and discharging load that has been determined in previous section; $P C P(t)$ is the charging and discharging profile. In the constraints, $S O C_{i}(t)$ is the state of charge of the ith PHEV at time $t, d_{i}$ shows the departure time of the ith PHEV from the parking lot, $\operatorname{SOC}_{i}\left(d_{i}\right)$ is the SOC of the ith PHEV at the departure time, $S O C_{i, \text { des }}$ is the desired SOC of the ith PHEV at the departure time, $V_{p u}^{k}(t)$ is the per-unit voltage of node $k$ at time $t, V_{m i n, p u}^{k}(t)$ is the minimum possible per-unit voltage of node $\mathrm{k}$ at time $\mathrm{t}, C R_{i}(t)$ and $D R_{i}(t)$ are respectively charging and discharging rates at time interval $t$. In addition, $C R_{i}^{\max }$ and $D R_{i}^{\max }$ are maximum values for the charging and discharging of ith PHEV at each time interval. $C_{\max }^{k}$ is the maximum feasible capacity of the parking at node $k . S O C_{i}(t)$ is clearly a positive variable that should be limited to the battery capacity. This restriction is certified in (6). Considering customers' 
satisfaction, it is assumed that the minimum SOC level at departure time for each PHEV should be greater than a definite value determined by the PHEV owner. This is met in (7). Equation (8) expresses that voltages of each node should be higher than a specified minimum level (in per-unit). The expression in (9) verifies that the charging and discharging should be capped to definite charge and discharge rates. The decision variable in the optimization problem is $x^{k}$, which determines the contribution of each candidate bus in taking total charging and discharging loads. In other words, $x^{k}$ implicitly determines the PHEV parking capacity at each candidate bus. The capacity of each parking is determined based on the variable $x^{k}$ according to (10). In the last constraint, i.e., (11), the capacity of each parking is capped to a maximum feasible value.

\section{CASE STUdy}

In this section, at first, the PCP is developed and then the proposed optimization problem is applied to a test feeder to verify the effectiveness of the introduced method. To calculate PCP, a typical household load profile is needed. Since we are concentrating on parking lots, the load profile is considered only during the presence of vehicles in parking, which according to Table II, the longest interval is from $7^{\mathrm{AM}}$ to $7^{\mathrm{PM}}$. The charger efficiency is assumed $88 \%$ [16]. The typical household load profile is available for one house in [17] and is shown in Fig. 1. The proposed method is applied to IEEE-34 node test feeder in this section. The test feeder is presented in Fig. 2, which has 6 spot loads and 27 distributed loads [18].

Six spot loads have a total load of $1067 \mathrm{~kW}$. We assume that $70 \%$ of this load is residential loads and the rest is small commercials and industrial loads. Therefore, with an average household load of $2.97 \mathrm{~kW}$, there would be a total of 252 houses. For distributed loads it is assumed that each phase has 3 customers, and so there will be a total number of 243 houses for distributed loads. So the total number of houses in IEEE-34 node test feeder is estimated to be equal to 495 based on (3). Now it is possible to obtain total network load profile. The calculated network load profile is shown in Fig. 3.

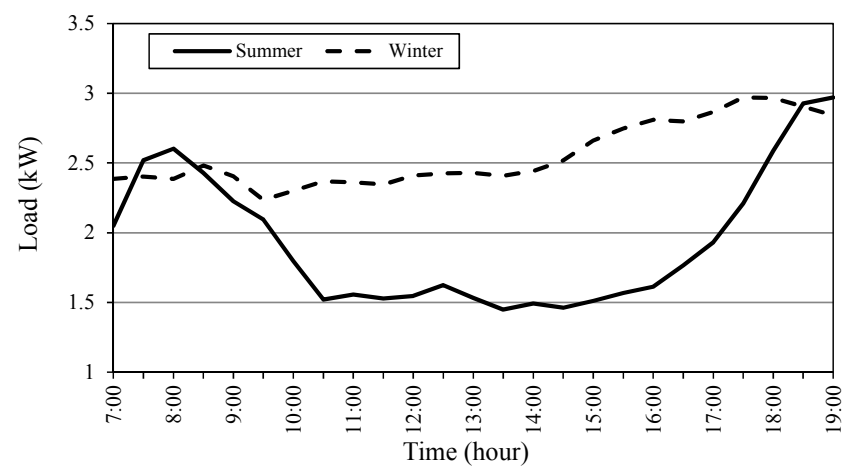

Fig. 1 Typical household load profile

Here, a sample PCP is developed and subsequently used in the numerical study. For more realistic results, the PCP is developed for two scenarios. Each of these scenarios considers a level of load growth as well as a PHEV penetration level. The amount of load growth and PHEV penetration levels are respectively taken from [17], [19]. First scenario is based on an average household load of about $3 \mathrm{~kW}$ and a PHEV penetration level of about $25.2 \%$. PCP for the second scenario is determined based on an average household load of about $5 \mathrm{~kW}$ and a PHEV penetration level of 52.9\%. Both developed PCPs are shown in Fig. 4. It should be noted that these PCPs are developed for the summer times.

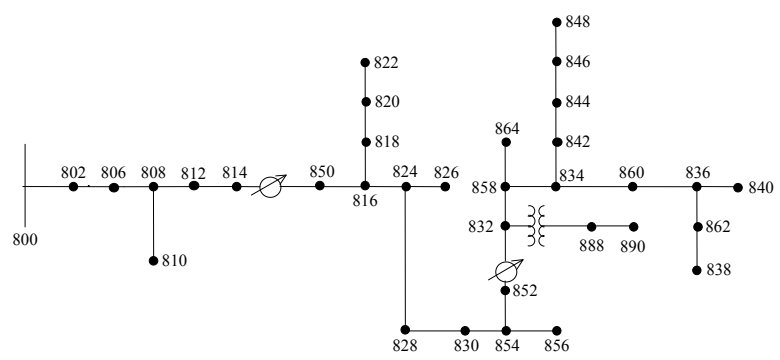

Fig. 2 IEEE-34 node test feeder topology

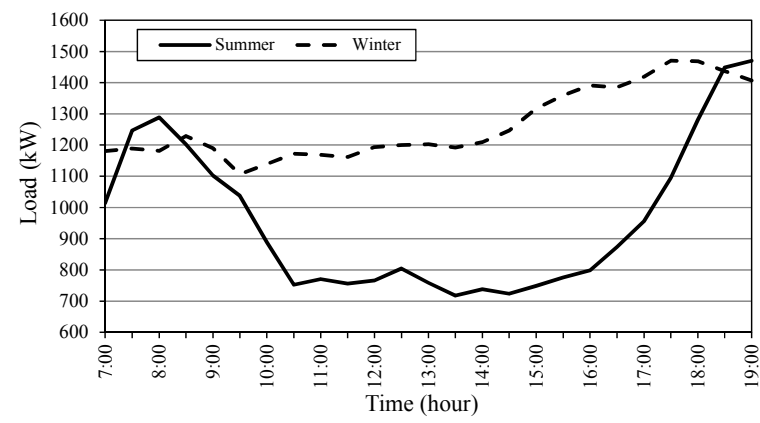

Fig. 3 Total network load profile
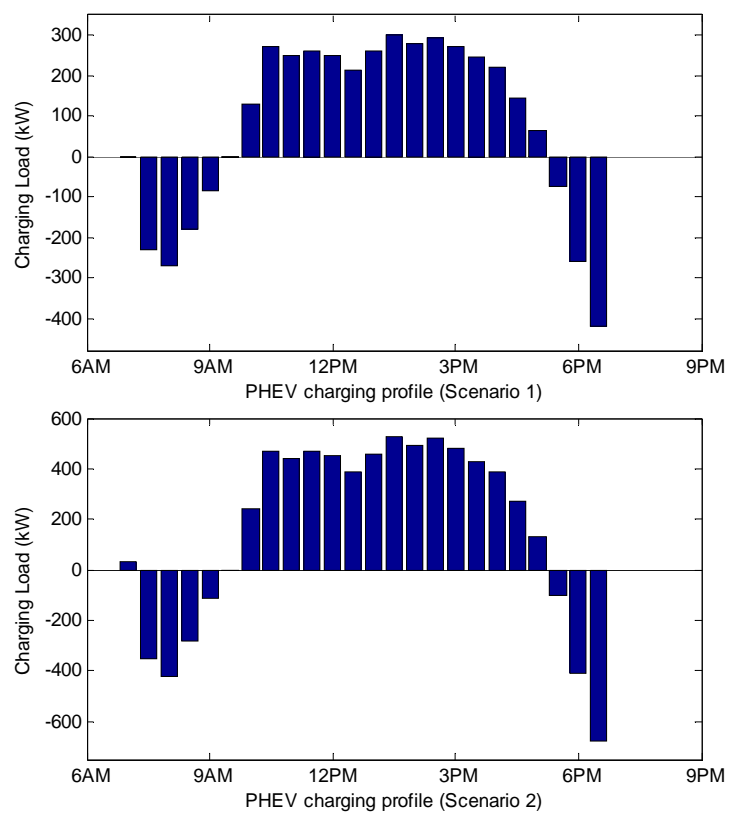

Fig. 4 Developed PCP for two scenarios defined in section V 
It is assumed that, $S O C_{i, d e s}$ is equal to 0.9 for all PHEVs. In addition, the minimum per-unit voltage for each node, i.e., $\mathrm{V}_{p u \text {,min }}^{k}$, is presumed 0.9. The candidate buses for constructing a PHEV parking lots are assumed to be buses number 808,810 , $820,822,826,828,834,838,846,856$ and, 864. When the simulations are run, the contribution of each candidate bus in taking total charging and discharging loads will be known. This contribution is shown as $\mathrm{x}^{\mathrm{k}}$ in (5).

Presented PCPs are defined as "load shapes" and inserted to OpenDSS software. Besides that, IEEE-34 node test feeder loads are modeled similar to Fig. 3. The OpenDSS software is linked with MATLAB and $\mathrm{x}^{\mathrm{k}}$ defined are calculated by solving the optimization problem, using the genetic algorithm (GA) method.

The study is investigated in two cases. In Case 1, the estimated number of PHEVs in each scenario is equally allocated to the candidate nodes. For example, in the scenario with 264 PHEVs, 24 PHEVs are allocated to each of 11 nodes. In Case 2, the proposed method is applied to optimally allocate PHEVs to the candidate nodes.

Running GA will result in the numbers presented in Tables VII in Case 2 for two scenarios. In addition, the resulted total losses from PHEV parking allocation process in two cases are presented in Table VIII.

TABLE VII

PHEV PARKING CAPACITY FOR EACH CANDIDATE NODE

\begin{tabular}{ccc}
\hline \hline Bus number & Scenario 1 & Scenario 2 \\
\hline 808 & 100 & 100 \\
810 & 18 & 47 \\
820 & 0 & 94 \\
822 & 17 & 0 \\
826 & 18 & 47 \\
828 & 15 & 70 \\
834 & 13 & 47 \\
838 & 28 & 47 \\
846 & 24 & 47 \\
856 & 15 & 31 \\
864 & 16 & 24 \\
Total & 264 & 554 \\
\hline \hline
\end{tabular}

TABLE VIII

TOTAL SYSTEM LOSSES WITH AND WITHOUT PHEV (FROM $7^{\mathrm{AM}}-7^{\mathrm{PM}}$ )

\begin{tabular}{ccccc}
\multirow{2}{*}{$\begin{array}{c}\text { Scenarios (Different PHEV } \\
\text { penetration and load growth } \\
\text { level) }\end{array}$} & \multicolumn{2}{c}{ Scenario 1 } & \multicolumn{2}{c}{ Scenario 2 } \\
\cline { 2 - 5 } & No & 264 & No & 554 \\
PHEVs & PHEVs & PHEVs & PHEVs \\
\hline Case 1 (random allocation) & 112.33 & 128.61 & 131.41 & 144.36 \\
Case 2 (optimall allocation) & 78.32 & 61.11 & 125.87 & 92.28 \\
\hline
\end{tabular}

As the objective of allocation is to minimize distribution system losses, PHEV charge and discharge loads are expected to be located near the source-bus as much as possible. Since, as we recede from the source, voltage will drop and the load will draw more current. It is clear from the results of Table VII that this point is met and maximum possible capacity (100) for each parking is taken for the nearest bus to the source. The presented results in Table VIII show that random allocation of PHEV parking lots makes the distribution system losses increase.
However, the optimal allocation of PHEV parking lots in the second case not only causes the lower total losses in comparison with the first case, but also reduces the losses compared to the case with no PHEVs. In addition, as the penetration level of PHEVs increases, the percentage of loss reduction obtains higher values due to the capability of $V 2 G$ in supplying more amounts of loads.

\section{CONCLUSION}

Centralized management and control of charging process of PHEVs can minimize losses in the power grid and flatten network load profile. In addition, V2G operation mode of PHEVs in charging parking lots, can make them as flexible loads that are used as distributed power sources. In this paper, a profile for PHEV charging and discharging is developed to flatten network load profile. Actual PHEV arrival and departure times to and from the parking, three types of PHEVs, and four classes of vehicles are considered in two scenarios with different load growth and PHEV penetration levels. The developed PCP in each scenario is used to determine size and location of PHEV parking lots to minimize distribution system losses. The developed PCP is applied to the test network for two introduced scenarios. The simulation results are presented as total number of PHEVs to be located in each candidate bus. It is clear from simulation results that if charging parking lot is not allocated properly total network losses may increase even more than $16 \%$. In addition, if the allocating process is optimally effectuated based on the proposed method, total distribution losses are reduced by up to $27 \%$.

\section{REFERENCES}

[1] Don Anair, Amine Mahmassani, "State of Charge: Electric Vehicles' Global Warming Emissions and Fuel-Cost Savings across the United States", April 2012.

[2] Paul Stenquist, "How Green Are Electric Cars? Depends on Where You Plug In", The New York Times, April 2012.

[3] FLUENCE and FLUENCE Z.E., "Life Cycle Assessment", October 2011.

[4] T. Markel, A. Simpson, "Plug-in Hybrid Electric Vehicle Energy Storage System Design" in Proc. Advanced Automotive Battery Conf., Baltimore, May 2006.

[5] C. Camus, C. M. Silva, T. L. Farias, and J. Esteves, "Impact of Plug-in Hybrid Electric Vehicles in The Portuguese Electric Utility System" in Proc. IEEE Power Engineering, Energy and Electrical Drives Conf., June 2009.

[6] M. Moradijoz, M. Parsa Moghaddam, M.R. Haghifam, E. Alishahi, "A Multi-Objective Optimization Problem for Allocating Parking Lots in A Distribution Network" in Electrical Power and Energy Systems, vol. 46, March 2013.

[7] M. Moradijoz, M.P. Moghaddam, "Optimum Allocation Of Parking Lots In Distribution Systems for Loss Reduction" in Power and Energy Society General Meeting, IEEE, July 2012.

[8] M. Moradijoz, A. Ghazanfarimeymand, M.P. Moghaddam, M.R. Haghifam, "Optimum Placement Of Distributed Generation and Parking Lots for Loss Reduction in Distribution Networks" in Electrical Power Distribution Networks (EPDC), 2012 Proceedings of 17th Conference, May 2012.

[9] E. Mohammadi, A. Foroughi, M. Rashidinejad, R. Fadaeinedjad, "Optimal allocation of parking lots and PV systems in distribution system for energy loss reduction and voltage profile improvement" in Electrical and Computer Engineering (CCECE), 2013 26th Annual IEEE Canadian Conference, May 2012.

[10] The NHTS Academy, "National Household Travel Survey", http://nhts.ornl.gov/. 
[11] Ahmad Pesaran, National Renewable Energy Laboratory, "Battery Requirements for Plug-In Hybrid Electric Vehicles - Analysis and Rationale", CA, December 2007.

[12] Michael Kintner-Meyer, Kevin Schneider, Robert Pratt, Pacific Northwest National Laboratory, "Impacts Assessment of Plug-in Hybridvehicles on Electric Utilities and Regional U.S. Power Grids, Part 1: Technical Analysis", November 2007.

[13] Electric Power Research Institute, "Distribution System Simulator (OpenDSS)", http://sourceforge.net/projects/electricdss/.

[14] University of New South Wales, Kuhu Gupta, Campus Planner at UNSW Facilities Management, "2013 Travel Survey and Campus Counts - Analysis Summary", April 2013, Australia.

[15] Global Parking Association Leaders Summit, "2013 Global Parking Survey - Report on Surveys", Dublin, September 2013.

[16] Soroush Shafiee, Mahmud Fotuhi-Firuzabad, Mohammad Rastegar, "Investigating the Impacts of Plug-in Hybrid Electric Vehicles on Power Distribution Systems", IEEE Transactions on Smart Grid, July 2012.

[17] The Australian Energy Market Operator, Retail Markets and Metering, http:/www.aemo.com.au/Electricity/Data/Metering/Load-Profiles, August 2013.

[18] Distribution Test Feeders, IEEE PES Distribution System Analysis Subcommittee's, Distribution Test Feeder Working Group, http://ewh.ieee.org/soc/pes/dsacom/testfeeders/feeder34.zip, August 2013.

[19] OAK Ridge National Laboratory, Stanton W. Hadley, "Impact of Plugin Hybrid Vehicles on the Electric Grid", October 2006. 